\title{
Critical care nursing in Colombia: the form
of a new critical care nursing association
}

Wilson Cañón RN; Grad Cert Clin Epidem, Grad Cert Educ Virtlss, Nurse Educator, Santander's Industrial University, Bucaramanga, Colombia:

Nubia Agudelo RN, Cardiology and Respiratory Care Nurse, EM University Hospital, Cúcuta, Colombia;

Josefina Manosalva ${ }^{1}$ RN; MSc (Educational and Social Development), Neurology Care Nurse, Associate Professor;

Fanny Rincón ${ }^{1}$ RN; MSc (Nursing), Cardiology and Respiratory Care Nurse, Associate Professor;

Luz Nelly Rivera ${ }^{1}$ RN; MSc (Nursing), Critical Care Nurse, Associate Professor;

Myriam Parra ${ }^{1}$ RN; MSc (Education), Cardiology and Respiratory Care Nurse, Associate Professor;

Sandra Rocío Guaqueta ${ }^{1}$ RN; MSc (Education), Cardiology and Respiratory Care Nurse, Assistant Professor;

Magda Lucía Flórez ${ }^{1}$ RN; MSc (Nursing), Critical Care Nurse, Assistant Professor;

Ana Maritza Gómez ${ }^{1}$ RN; MSc (Nursing and Teaching), Cardiology and Respiratory Care Nurse, Assistant Professor;

Martha Cecilia Triana ${ }^{1}$ RN; MSc (University Teaching), Critical Care Nurse, Assistant Professor.

${ }^{1}$ Nursing Faculty, National University, Bogotá, Colombia.

E-mail: wilcamo32@yahoo.com

Key Words: Colombia * critical care * committee * history * nursing

\section{SUMMARY}

- Intensive care services in Colombia have grown in recent years due to the high demand of critically ill patients.

- A group of nurse leaders in Colombia were interested in the development of critical care nursing and, after much hard work, created a critical care nursing committee to help and to represent the voice of critical care nurses in Colombia.

- This paper summarises the formation of a new national critical care nursing organisation in Colombia.

\section{INTRODUCTION}

Critical care nursing, as a specialty, has grown internationally. This growth has been supported through the development of educational programs in response to the high demands of hospitals, which have opened intensive care units to provide intensive therapy for critically ill patients.

In Colombia, according to data from the Colombian Association of Faculties of Nursing, there are currently nine graduate degree programs that lead to a qualification in critical care nursing, of which seven programs specialise in adult care and two specialise in paediatric care.

In our country, the idea of forming a nursing organisation in critical care began in the 1980s, when some nurses saw the need to help develop nursing in this field. However, there were many difficulties at this time, which made it impossible. Later, in the 1990s, a second attempt was made to establish a formal organisation, but this too, failed.

\section{CREATING A NEW COLOMBIAN ORGANISATION}

In August 2005, the 9th Congress of the World Federation of Societies of Intensive and Critical Care Medicine (WFSICCM) was held in Buenos Aires, Argentina. During the conference, the Council of the World Federation of Critical Care Nurses (WFCCN) met with leaders of critical care nursing organisations from Latin America, with the purpose of establishing a federation in the region. Their aim was to improve the influence and contribution of nursing to the healthcare of critically ill patients, and to be a collective voice for all the nurses that work in critical care (Albarran, 2005). One of the participant nurses, who was a critical care nursing leader in Colombia, assisted in these meetings and she also took on the task of inviting other nurses to help to advance the formation of a Colombian organisation (Agudelo et al., 2007).

The commitment assumed by these Latin American nursing leaders was realised after several meetings, of which the first was held in June 2006, in Margarita, Venezuela, during the 11th Congress of Critical Medicine and the 3rd Congress of the Venezuelan Society of Nursing in Intensive Care (SOCVECI). It was during this meeting that the Latin American Federation of Intensive Care Nurses (Federación Latinoamericana de Enfermería en Cuidado Intensivo: FLECI) was founded, and its name approved (Williams, 2007).

Also, in June 2006, an international critical care meeting and conference was held in the city of Cúcuta, Colombia. Representatives from WFCCN and the National Association of Nurses from Colombia also attended this meeting, as well as several Colombian intensive care nurse leaders. They met to discuss plans for the formation of a critical care nursing organisation in Colombia and possible structures (Agudelo et al., 2007; Williams, 2007). 
In Lima, Peru, in November of the same year the launch of the Latin American Federation of Intensive Care Nurses (FLECI) took place and the Declaration of Lima was approved and signed, and the FLECI constitution was approved. The Federation was founded with the participation of nine countries: Argentina, Bolivia, Brazil, Chile, Colombia, Mexico, Peru, Uruguay, and Venezuela. The formation of FLECI was supported by WFCCN (Fulbrook, 2007; Williams, 2007). Four Colombian nursing leaders were in attendance in Lima, and the FLECI logo was presented and proposed by Colombia's delegation, and was subsequently approved by the new FLECI Council.

In Lima, Peru, Colombian critical care nursing leaders formed a management group, working under the title of the Colombian Association of Critical Care Nurses (ACECC), as the organisation was called initially. The group was comprised of ten critical care nurses from clinical, academic, and research backgrounds (see picture 1).

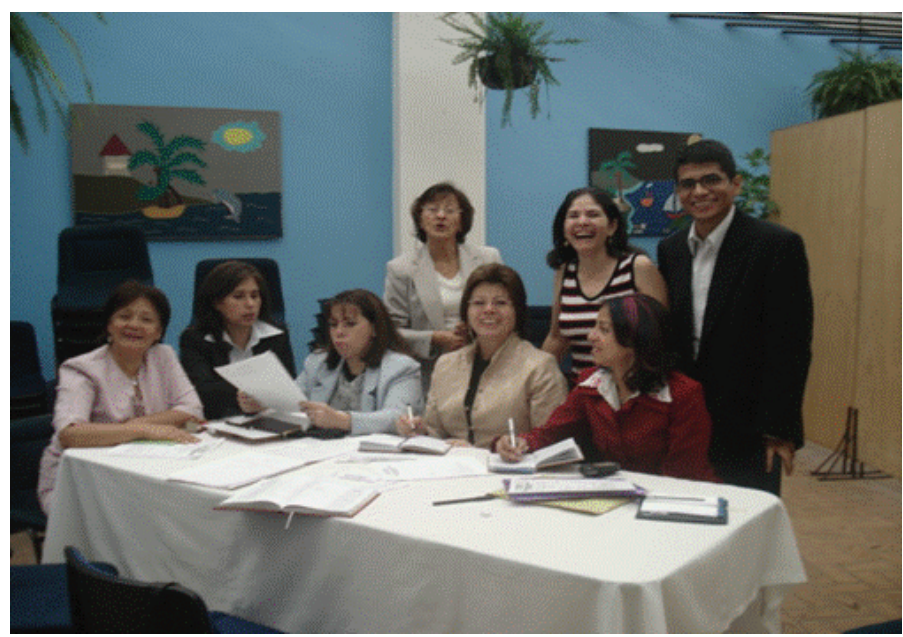

Picture 1. First Meeting of Colombia leaders in Bogotá, Colombia, January, 2007

During 2007, the ACECC Management Group met monthly and consulted widely with critical care nursing colleagues, gaining their support. During the 6th Congress of the Colombian Association of Critical Medicine and Intensive Care $(\mathrm{AMCl})$, the Management Group held a meeting which was attended by many nurses from all over the whole country. A number of different association proposals were discussed.

At an international level, ACECC applied for membership of WFCCN. The WFCCN Council met during the 4th WFCCN Congress, which was held in Sun City, South Africa in August 2007. The Council voted to support ACECC's membership and, during the Congress, Nubia Agudelo was formally presented with a memorial plaque (see picture 2) to commemorate the admittance of ACECC to WFCCN. On 07 November, 2007, the ACECC Management Group was accepted as the Nursing Committee of Critical Care of the National Association of Nurses from Colombia (CECC-ANEC, 2007) (see picture 3).

During the WFCCN Council meeting it was also agreed that its journal - Connect: The World of Critical Care Nursing - would be developed so that it could be available in Spanish, as well as English. This strategy was agreed as a direct consequence of the formation of FLECI, and also as part of WFCCN's broader strategy to improve worldwide communication between critical care nurses. In order to advance this strategy, a Spanish-speaking editorial board was established for the journal, with representatives from all the $\mathrm{FLECl}$ national associations. A member of the ACECC Management Group (Wilson Cañon) represents Colombia.

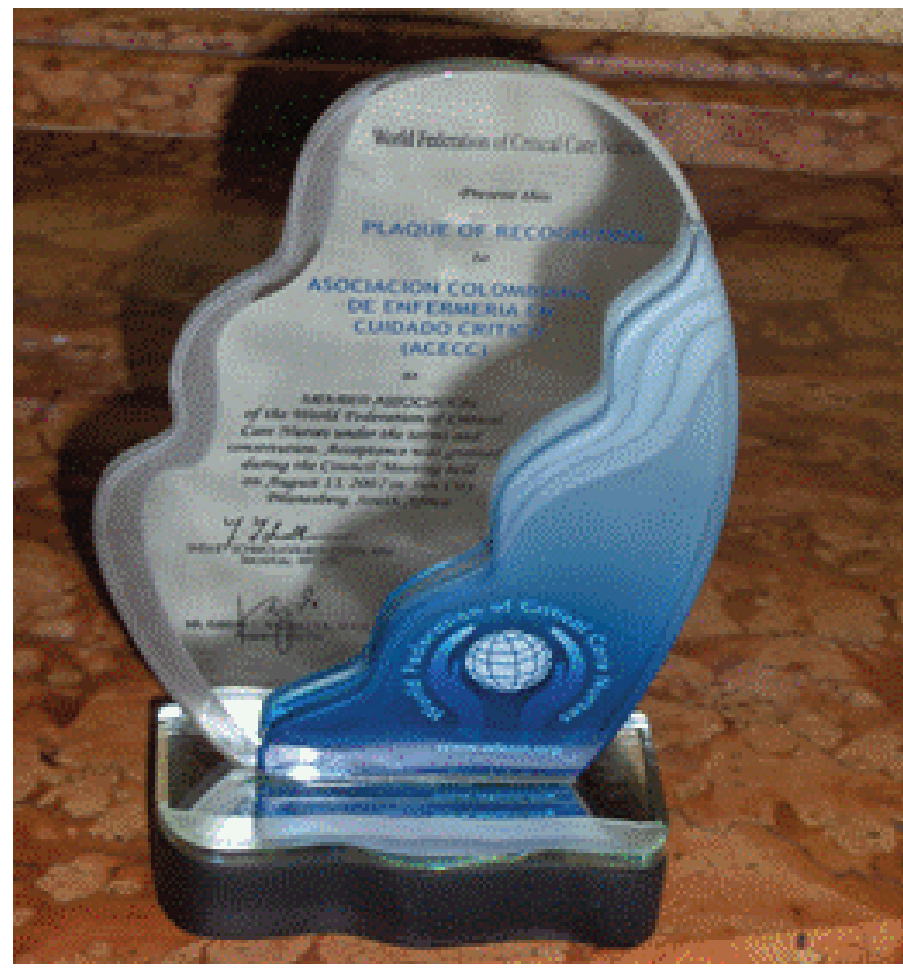

Picture 2. The memorial plaque to commemorate the admission of the Colombian association to WFCCN

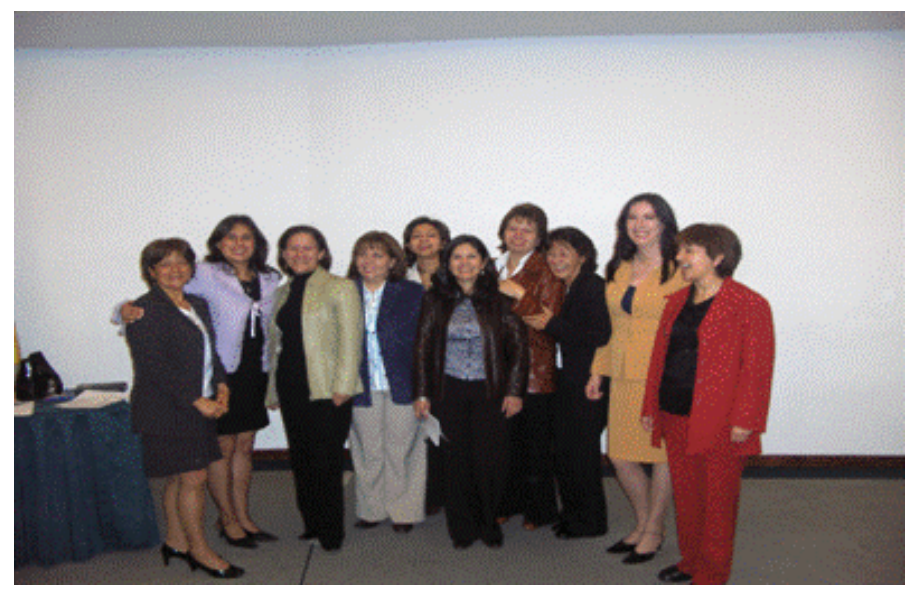

Picture 3. The new CECC-ANEC committee with the Chairwoman of the National Association of Nurses from Colombia, Bogotá, Colombia

On 23 November, 2007, during the 1st International Conference Meeting and 2nd Conference Meeting of Nursing in Critical Care, organised by the National University and the original Management Group, CECC-ANEC was officially launched in Colombia, with the participation of national critical care nursing leaders and the support of representatives from WFCCN, FLECI and ANEC (picture 4).

As part of its plan to improve international communication, one member of CECC-ANEC (Wilson Cañon) traveled to Australia, supported by WFCCN, to study English. He also visited various public and private hospitals to learn about the techniques and practices of Australia's critical care nurses (picture 5). 


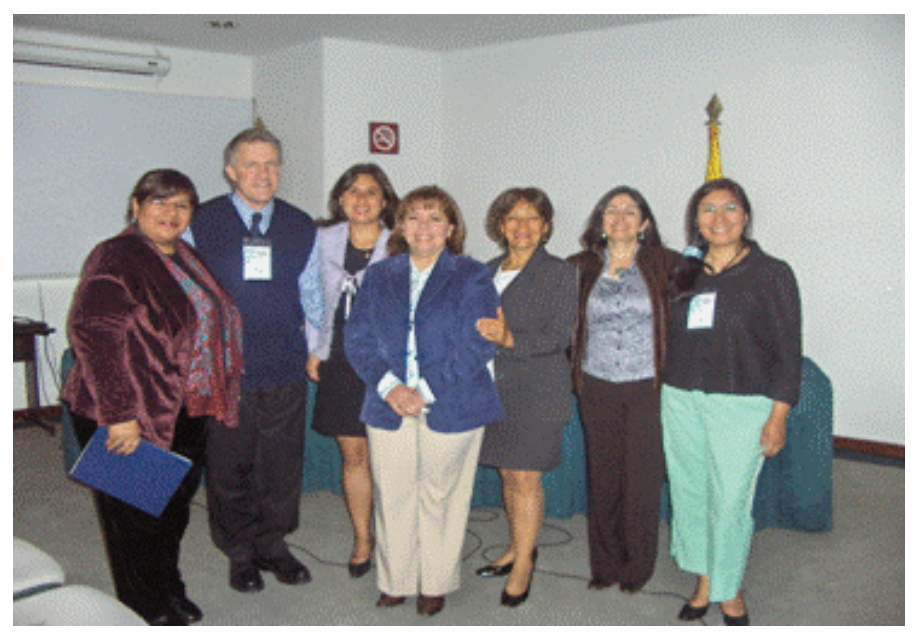

Picture 4. Colombia, November, 2007: launch of the Colombian Committee of Critical Care Nurses with the participation of representatives from the Councils of WFCCN and FLECI

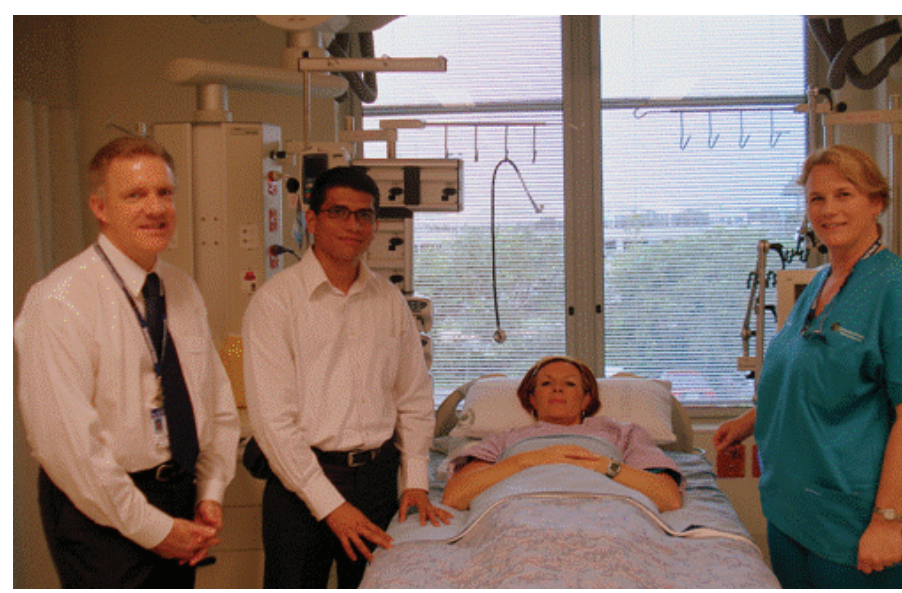

Picture 5. A Colombian nurse learning the practice of Australian's critical care nursing (Gold Coast - Queensland, Australia, 2007)

\section{CONCLUSION}

In conclusion, there are many advances in the development of critical care nursing occurring in Colombia and the formation of a national critical care nursing organisation will do much to enhance further development. Our new organisation provides an avenue through which we can support and motivate our colleagues to achieve our goal of excellence in the provision of nursing care to individuals in vulnerable states of health. Colombian critical care nurses recognise the importance of continuing to develop nursing science and the professional contribution we can make in our country and the world.

\section{NOTE}

The authors are all founder members CECC-ANEC.

\section{REFERENCES}

Agudelo N, Cañon W, Florez ML, Gomez AM, Guaqueta SR, Manosalva J, et al. (2007). It is created a nursing committee of critical care from the National Association of Nurses from Colombia. ANEC 67, 34-35.

Albarran J (2005). World Federation of Critical Care Nurses Council Meeting, August 2005, Buenos Aires, Argentina. CONNECT: The World of Critical Care Nursing 4 (2), 39-40.

Fulbrook P (2007). What in the world have we done? CONNECT: The World of Critical Care Nursing. 5 (3), 65.

Williams G (2007). Latin American critical care events. CONNECT: The World of Critical Care Nursing 5 (3), 83-84.

Nursing Committee of Critical Care (2007). National Association of Nurses from Colombia. ANEC. Ruling No. 005, 07 November 2007. 